\title{
PENGARUH BERBAGAI JENIS PUPUK KANDANG TERHADAP PERTUMBUHAN TANAMAN KRISAN POTONG (Chrysanthemum sp.)
}

\author{
Chintya Ayu Dwi Cahya ${ }^{1^{*}}$ dan Ferdinant ${ }^{2}$ \\ 1. Mahasiswa Program Studi Budidaya Tanaman Hortikultura, Jurusan Budidaya Tanaman \\ Pangan,Politeknik Pertanian Negeri Payakumbuh \\ 2. Dosen Program Studi Budidaya Tanaman Hortikultura, Jurusan Budidaya Tanaman Pangan \\ Politeknik Pertanian Negeri Payakumbuh \\ *Email :chintyaayudwic@gmail.com
}

\begin{abstract}
ABSTRAK
Unsur hara merupakan salah satu faktor penting dalam keberhasilan budidaya tanaman krisan potong. Beberapa upaya dalam penyediaan unsur hara ialah dengan menambahkan pupuk organik. Pemberian pupuk yang tepat dan unsur hara yang seimbang dilakukan untuk mendapat pertumbuhan dan hasil bunga krisan yang diinginkan. Tujuan untuk mengetahui jenis pupuk kandang yang terbaik terhadap pertumbuhan vegetatif dan generatif tanaman krisan potong. Metode yang digunakan berupa studi literatur terkait pengaruh beberapa jenis pupuk kandang terhadap pertumbuhan tanaman krisan potong. Hasil yang didapatkan pertumbuhan vegetatif tanaman krisan potong yang terbaik terdapat pada perlakuan pupuk kandang sapi yaitu pada parameter tinggi tanaman $\backslash$ panjang daun. lebar daun dan jumlah ruas batang, sedangkan panjang tangkai daun pada perlakuan pupuk kandang sapi lebih rendah dari pada pupuk kandang ayam serta diameter batang lebih rendah dari perlakuan pupuk kandang ayam, domba dan kelinci. Sedangkan hasil penelitian pertumbuhan generatif tanaman krisan potong yang terbaik terdapat pada perlakuan pupuk kandang ayam.
\end{abstract}

Kata kunci : Unsur hara, pupuk kandang, krisan, pertumbuhan vegetatif, pertumbuhan generatif

\section{PENDAHULUAN}

Tanaman krisan (Chrysanthemum sp.) merupakan salah satu jenis bunga yang cukup populer di Indonesia, karena memiliki bentuk indah, warna yang beranekaragam, mudah dirangkai serta memiliki kesegaran bunga yang lama. Tanaman hias ini memiliki nilai ekonomi tinggi dan potensial untuk dikembangkan. Krisan dalam perdagangan internasional adalah tanaman bunga potong paling penting ketiga setelah mawar dan anyelir (Nxumalo dan Wahome, 2010). Tanaman krisan umumnya dibudidayakan dan dikomersilkan dalam bentuk bunga potong dan tanaman dalam pot. Sebagai bunga potong krisan digunakan sebagai bahan dekorasi dalam bentuk rangkaian besar.

Kendala yang sering dihadapi dalam melakukan budidaya tanaman krisan adalah rendahnya kesuburan tanah yang akan berpengaruh terhadap pertumbuhan dan produksi tanaman. Pada fase pertumbuhan vegetatif dan awal fase generatif, tanaman membutuhkan ketersediaan unsur hara yang cukup agar mampu meningkatkan pertumbuhan tanaman. Upaya yang dapat dilakukan untuk meningkatkan dan mengoptimalkan pertumbuhan tanaman krisan yaitu dengan penambahan pupuk kandang dalam memenuhi unsur hara tanaman. Menurut Samekto (2006), pemupukan adalah pemberian pupuk untuk menambah persediaan unsur hara yang dibutuhkan tanaman dalam meningkatkan produksi dan mutu hasil tanaman yang dihasilkan. Pupuk kandang adalah salah satu pupuk organik yang memiliki kandungan hara yang dapat mendukung kesuburan tanah dan pertumbuhan mikroorganisme dalam tanah. Pupuk kandang adalah pupuk yang berasal dari kandang ternak, baik berupa kotoran padat (feses) yang bercampur sisa makanan maupun air kencing (urine), seperti sapi, ayam, kelinci dan kambing. Pupuk kandang tidak hanya mengandung unsur makro seperti nitrogen $(\mathrm{N})$, fosfat $(\mathrm{P})$ dan kalium (K), namun pupuk kandang juga mengandung unsur mikro seperti kalsium (Ca), magnesium ( $\mathrm{Mg}$ ), dan mangan (Mn) yang dibutuhkan tanaman serta berperan dalam memelihara keseimbangan hara dalam tanah dan tanaman krisan potong. 


\section{METODE PELAKSANAAN}

Data dan informasi diperoleh dari studi literatur terkait penggunaan berbagai pupuk kandang terhadap pertumbuhan tanaman krisan potong.

\section{PEMBAHASAN}

Berdasarkan penelitian Putra dan Histifarina (2010) memiliki data vegetatif tertinggi terdapat pada perlakuan pupuk kandang sapi yaitu tinggi tanaman, panjang daun, lebar daun dan jumlah ruas batang. Panjang tangkai daun pada perlakuan pupuk kandang sapi lebih rendah dari pada pupuk kandang ayam serta diameter batang lebih rendah dari pupuk kandang ayam, domba dan kelinci.

Sedangkan data pertumbuhan generatif berdasarkan penelitian Putra dan Histifarina (2010) memiliki data generatif tanaman krisan yang terbaik terdapat pada pupuk kandang ayam yaitu diameter bunga dan jumlah kuntum bunga, sedangkan panjang tangkai bunga lebih rendah dibandingkan dengan pupuk kandang domba, kelinci dan sapi.

Penggunaan pupuk kandang sapi pada pertumbuhan vegetatif tanaman krisan sangat bagus dibandingkan dengan pupuk kandang lainnya. Hasil penelitian Putra, Maghfoer dan Koesriharti (2017), menunjukkan bahwa pemberian pupuk kandang sapi 20 ton ha-1 lebih dapat meningkatkan tinggi tanaman krisan dibandingkan dengan penggunaaan pupuk kandang ayam. Hal ini didukung dengan hasil penelitian Putra dkk (2017) dimana pertumbuhan vegetatif tanaman krisan sangat terlihat berbeda yaitu tinggi tanaman $79,05 \mathrm{~cm}$, jumlah daun 42,61 , diameter batang $0,52 \mathrm{~cm}$ dibandingkan dengan menggunakan pupuk kandang ayam, domba dan kelinci.

Semakin tinggi dosis pupuk kandang sapi yang digunakan maka pertumbuhan pada tanaman krisan juga semakin bagus. Terlihat pada hasil penelitian dari Nugroho, Histifarina, dan Elonard (2019) pada dosis pupuk kandang sapi $4 \mathrm{~kg} / \mathrm{m}^{2}$ terlihat lebih dominan pertumbuhannya dibandingkan dengan dosis 2 $\mathrm{kg} / \mathrm{m}^{2}$ dan $3 \mathrm{~kg} / \mathrm{m}^{2}$ yaitu tinggi tanaman 74,8 $\mathrm{cm}$, jumlah daun 40,4 helai, panjang daun 7,9 $\mathrm{cm}$ dan lebar daun 3,9 $\mathrm{cm}$. Ini dikarenakan kandungan didalam pupuk kandang sapi terdapat kadar air yang tinggi, meskipun unsur hara $\mathrm{N}$ yang dibutuhkan tanaman krisan sedikit diambil tetapi serat yang didalamnya mampu memudahkan akar tanaman krisan untuk menyerap unsur N tersebut. Pranata (2010) menyatakan diantara jenis pupuk kandang, kotoran sapilah yang mempunyai kadar serat yang tinggi seperti selulosa, hal ini terbukti dari hasil pengukuran parameter $\mathrm{C} / \mathrm{N}$ rasio yang cukup tinggi $>40$, disamping itu pupuk ini juga mengandung unsur hara makro seperti $0,5 \mathrm{~N}, 0,25 \mathrm{P}_{2} \mathrm{O}_{5}, 0,5 \% \mathrm{~K}_{2} \mathrm{O}$ dengan kadar air $0,5 \%$ dan juga mengandung unsur mikro esensial lainnya.

Organ penting pada tanaman adalah daun dikarenakan sebagai tempat berlangsungnya fotosintesis. Sesuai dengan yang dikemukakan Sitompul dan Guritno (1995), bahwa banyaknya jumlah daun menentukan luas permukaan daun. Jumlah daun yang semakin banyak maka jumlah intensitas cahaya yang diterima juga semakin banyak. Tanaman yang mengandung klorofil mampu menyerap cahaya yang kemudian digunakan dalam fotosintesis. Hasil dari fotosintesis akan menentukan ketersediaan energi untuk pertumbuhan dan perkembangan tanaman (Ashari, 1995). Sesuai dengan pendapat Warnita (2015) daun merupakan organ untuk melakukan fotosintesis yang dapat menghasilkan karbohidrat yang digunakan untuk pertumbuhan dan perkembangan, pertambahan jumlah daun akan menyebabkan banyaknya cahaya, $\mathrm{CO}_{2}$ dan air yang masuk melalui stomata daun sehingga dapat meningkatkan fotosintesis, dengan meningkatnya fotosintesis akan meningkatkan karbohidrat yang banyak sehingga dapat digunakan untuk meningkatkan pertumbuhan tanaman secara keseluruhan.

Tinggi tanaman akan menentukan panjang tangkai bunga potong krisan, dimana semakin tinggi tanaman maka semakin panjang tangkai bunga yang dihasilkan. Panjang tangkai adalah salah satu nilai terpenting dalam bunga potong. Seperti yang dijelaskan Kazaz (2010) nilai penting untuk pemasaran bunga krisan potong adalah panjang tangkai, begitu juga dengan bunga potong yang lain. Panjang tangkai akan mempengaruhi lama kesegaran bunga 
(vaselife) sehingga semakin panjang tangkai bunga, masa simpan bunga tersebut semakin lama.

Pertumbuhan generatif pada tanaman krisan terdapat pada Tabel 3 menunjukkan hasil dominan yang paling bagus ialah menggunakan pupuk kandang ayam yaitu diameter bunga $5,93 \mathrm{~cm}$ dan jumlah kuntum bunga 12. Hal ini menunjukkan bahwa kandungan di dalam pupuk kandang ayam sangat membantu dalam pertumbuhan generatif tanaman krisan. Menurut Wiryanta dan Bernardinus (2002) di dalam pupuk

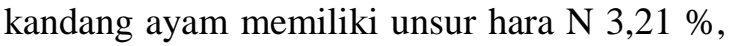
P2O5 3,21 \%, K2O 1,57 \%, Mg 1,44 \%, Mn 250 ppm dan Zn 315 ppm.

Perlakuan pupuk kandang ayam memilki struktur dengan butiran halus yang mudah terdekomposisi dengan cepat serta memiliki kelebihan dalam kecepatan penyediaan unsur hara setelah terdekomposisi. Berdasarkan data yang disajikan pada Tabel 3 menunjukkan bahwa hasil pertumbuhan generatif tanaman krisan terlihat bagus pada perlakuan pupuk kandang ayam yang diduga pada saat pertumbuhan generatif seperti pembungaan tanaman banyak memerlukan zat makanan seperti unsur nitrogen dan fosfor yang dibutuhkan. Pupuk kandang ayam yang sudah terdekomposisi dengan cepat memberikan zat esensial lebih tinggi dibandingkan pupuk kandang sapi. Sebagaimana pendapat Sutejo (2005), menyatakan bahwa pada saat pembentukan kuncup bunga, tanaman banyak menyerap unsur hara nitrogen dan fosfor yang dapat mempercepat pembungaan.

Kandungan unsur $\mathrm{N}$ yang terdapat didalam pupuk kandang ayam juga sangat diperlukan untuk merangsang pembesaran diameter bunga krisan, disebabkan tanaman krisan akan terlihat sempurna saat memasuki fase generatif. Sejalan dengan pendapat Harry (1994) pupuk yang mengandung $\mathrm{N}$ juga membantu mempercepat umur pembungaan dan panen serta dapat meningkatkan diameter bunga sehingga bunga lebih besar. Begitu juga dengan penjelasan Sutater dan Sanjaya (1992) bahwa unsur $\mathrm{N}$ yang diterima tanaman pada fase pembungaan akan mempengaruhi diameter bunga.
Selain faktor dari pupuk kandang dan organ tanaman krisan itu sendiri, syarat tumbuh juga sangat mempengaruhi pertumbuhan dan perkembangan tanaman krisan. Salah satunya adalah ketinggian tempat. Ketinggian tempat penelitian tanaman krisan yang dilakukan oleh Putra dan Histifarina (2010) adalah $1.200 \mathrm{~m}$ dpl dan Putra, Maghfoer dan Koesriharti (2017) adalah $\pm 950 \mathrm{~m}$ dpl. Pada ketinggian tersebut tanaman krisan mampu tumbuh dan berkembang dengan baik dan memberikan hasil bunga yang bagus disebabkan ketinggian tempat untuk tanaman krisan berkisar antara $650-1.200 \mathrm{~m}$ dpl. Hal ini disejelaskan dalam International Chrysanthemum Society (2002), bahwa krisan umumnya dibudidayakan dan tumbuh baik di dataran medium sampai tinggi pada kisaran 650 hingga $1.200 \mathrm{~m}$ dpl. Begitu pula dengan pendapat Sihombing (2009), krisan bunga potong dapat tumbuh baik pada ketinggian $650-1.200 \mathrm{~m}$ dpl.

Suhu rata-rata yang ada tempat penelitian Putra dan Histifarina (2010) adalah $18-22{ }^{\circ} \mathrm{C}$ dan Putra, Maghfoer dan Koesriharti (2017) adalah $18-24{ }^{\circ} \mathrm{C}$. Ini juga salah satu syarat tumbuh yang mempengaruhi pertumbuhan tanaman krisan. Suhu ini berfungsi untuk memberikan banyaknya pencahayaan matahari yang akan diterima oleh tanaman krisan baik untuk pertumbuhan vegetatif maupun generatif. Suhu rata-rata pada masing-masing tempat penelitian masih termasuk kategori yang diinginkan oleh tanaman krisan. Suhu harian untuk tanaman krisan biasanya berkisar antara $17-30{ }^{\circ} \mathrm{C}$. Tetapi setiap memasuki fase vegetatif dan generatif suhu yang dibutuhkan oleh tanaman krisan juga akan berbeda. Sesuai dengan pernyataan Khattak dan Pearson (1997) bahwa krisan dapat tumbuh pada kisaran suhu harian antara 17 sampai $30{ }^{\circ} \mathrm{C}$. Pada fase vegetatif, kisaran suhu harian pada siang hari 22 sampai $28{ }^{\circ} \mathrm{C}$ sedangkan pada malam hari tidak melebihi $26{ }^{\circ} \mathrm{C}$. Sedangkan untuk fase generatif dinyatakan oleh Wilkins (1990) suhu harian ideal pada fase generatif adalah 16 sampai $18{ }^{\circ} \mathrm{C}$. Jika suhu lebih dari $25^{\circ} \mathrm{C}$ akan mengganggu proses inisiasi pada pembungaan tanaman krisan yang dijelaskan oleh Maaswinkel dan Sulyo (2004) pada suhu di atas $25{ }^{\circ} \mathrm{C}$, proses inisiasi bunga akan terhambat dan menyebabkan pembentukan 
bakal bunga juga akan terhambat. Suhu yang terlalu tinggi jugaakan mengakibatkan bunga yang dihasilkan cenderung berwarna kusam, pucat dan memudar sehingga akan mengurangi minat konsumen untuk membeli bunga krisan tersebut.

Kelembaban udara juga mempengaruhi pertumbuhan tanaman krisan. Penelitian Putra, Maghfoer dan Koesriharti (2017) memiliki kelembaban udara sekitar tempat penelitian adalah $86 \%$, dimana kelembaban tersebut masih diinginkan oleh tanaman krisan. Seperti yang dijelaskan oleh Mortensen (2000) tanaman krisan membutuhkan kelembaban 90 - $95 \%$ pada awal pertumbuhan untuk pembentukan akar, sedangkan pada tanaman dewasa pertumbuhan optimal dicapai pada kelembaban udara sekitar $70-85 \%$. Hal ini juga diperkuat oleh pendapat Sihombing (2009) untuk pertumbuhan akar pada awal tanaman dibutuhkan kelembaban 90 - $98 \%$, sedangkan untuk pembungaan kelembaban yang dibutuhkan adalah $70-80 \%$.

Krisan tipe spray dalam satu tangkai bunga terdapat 10-20 kuntum bunga berukuran kecil. Seperti yang dijelaskan oleh Sari (2010) jumlah bunga mempunyai hubungan yang erat dengan panjang tangkai sehingga semakin banyak jumlah kuntum bunga maka secara tidak langsung tangkai bunga juga semakin panjang sehingga sering dikategorikan sebagai bunga yang berkualitas baik.

Kualitas bunga krisan potong merupakan faktor utama penentu preferensi konsumen. Kualitas dan mutu bunga adalah faktor yang sangat mempengaruhi harga jual bunga krisan. Berdasarkan hasil penelitian didapatkan ukuran bunga yang banyak diinginkan konsumen adalah bunga dengan grade A dengan diameter $4,1-5 \mathrm{~cm}$, panjang tangkai bunga minimum $70 \mathrm{~cm}$, bunga segar, tangkai bunga kuat, lurus dan tidak pecah. Sedangkan untuk grade B dengan diameter bunga 3-4 cm, panjang tangkai bunga minimum $61 \mathrm{~cm}$, bunga segar, tangkai bunga kuat, lurus dan tidak pecah. Kategori tersebut didukung pendapat dari Sutanto (2013) tanaman krisan yang dipanen merupakan tanaman krisan yang sesuai dengan kriteria panen salah satunya adalah bunga dalam keadaan setengah mekar.
Bunga potong krisan, preferensi konsumen berkaitan dengan jenis yang digunakan, warna bunga, ukuran bunga, bentuk bunga, ketegaran tangkai bunga, vaselife, dan harga. Bunga potong yang tidak berkualitas baik bukan menjadi pilihan bagi konsumen dalam melakukan pembelian. Hasil penelitian Reid (2005) di Amerika Serikat menunjukkan bahwa, rendahnya kualitas bunga potong menyebabkan konsumen lebih banyak menggunakan tanaman hias berbunga dan berdaun indah untuk mempercantik rumahnya.

\section{KESIMPULAN}

1. Pupuk kandang yang berpengaruh terhadap pertumbuhan vegetatif tanaman krisan adalah pupuk kandang sapi diikuti kelinci, ayam dan domba.

2. Pupuk kandang yang berpengaruh terhadap pertumbuhan generatif tanaman krisan adalah pupuk kandang ayam diikuti kelinci, domba dan sapi.

Untuk memperoleh hasil yang lebih baik pada budidaya tanaman krisan sebaiknya menggunakan kombinasi pupuk kandang sapi dan ayam.

\section{DAFTAR PUSTAKA}

Ashari. 1995. Pengaruh Penambahan Cahaya Pada 3 Varietas Krisan (Chrysanthemum morifolium) Tipe Spray. Jurnal Produksi Tanaman Vol. 5 No. 1, Januari 2017: 77 - 83 ISSN: 2527-8452

Harry. 1994. Seruni atau Bunga Emas Golden Flower. https://adoc.tips. Diakses pada tanggal 06 Juni 2020

International Chrysanthemum Society. 2002. Budidaya Krisan Bunga Potong Part 1. balithi.litbang.pertanian.go.id. diakses pada tanggal 27 Juli 2020

Kazaz. 2010. Respon Dua Kultivar Tanaman Krisan (Chrysanthemum morifolium) Pada Berbagai Lama Penambahan Cahaya Buatan. Jurnal Produksi Tanaman, Volume 2, Nomor 1, Januari 2014, hlm. 10-16

Khattak dan Pearson. 1997. Budidaya Krisan Bunga Potong 1. 
balithi.litbang.pertanian.go.id. diakses pada tanggal 27 Juli 2020

Maaswinkel dan Sulyo. 2004. Budidaya Krisan Bunga Potong Part 1. balithi.litbang.pertanian.go.id. diakses pada tanggal 27 Juli 2020

Mortensen. 2000. Budidaya Krisan Bunga Potong Part 1. balithi.litbang.pertanian.go.id. diakses pada tanggal 27 Juli 2020

Nugroho, E.D.S., Histifarina, D., dan Elonard, A. 2019. Respon Pertumbuhan Tanaman Krisan Potong (Chrysanthemum indicum L.) Varietas Ririh Terhadap Dosis Pupuk Kotoran Sapi dan Konsentrasi Bourine. Balai Penelitian Tanaman Hias. Jur. Agroekotek 11 (1) : 23 - 34, Juli 2019

Nxumalo dan Wahome. 2010. Respon Dua Kultivar Tanaman Krisan (Chrysanthemum morifolium) Pada Berbagai Lama Penambahan Cahaya Buatan. Jurnal Produksi Tanaman, Volume 2, Nomor 1, Januari 2014, hlm. 10-16

Pranata. 2010. Respon Pertumbuhan Tanaman Krisan Potong (Chrysanthemum indicum L.) Varietas Ririh Terhadap Dosis Pupuk Kotoran Sapi dan Konsentrasi Bourine. Balai Penelitian Tanaman Hias. Jur. Agroekotek 11 (1) : 23 - 34, Juli 2019

Putra, S., dan Histifarina, D. 2010. Respon Beberapa Varietas Krisan Terhadap Penggunaan Pupuk Organik. Balai Pengkajian Teknologi Pertanian Jawa Barat

Putra, M. F.D., Maghfoer, M. D., dan Koesriharti. 2017. Pengaruh Jenis Pupuk Kandang dan Dosis Pupuk NPK Pada Hasil Tanaman Krisan (Chrysanthemum sp.). Jurnal Produksi Tanaman Vol. 5 No. 4, April 2017: 670 - 676 ISSN : 2527-8452

Reid. 2005. Preferensi Konsumen Terhadap Krisan Bunga Potong dan Pot. Balai Penelitian Tanaman Hias. J. Hort. 24(4):363-372. 2014
Samekto. 2006. Uji Empat Jenis Pupuk Kandang Terhadap Pertumbuhn dan Hasil Tanaman Cabai Keriting (Capsicum annum L.). Jurnal AGRIFOR Volume XII Nomor 1, Maret 2013.

Sari. 2010. Pengaruh Lama Penyinaran Tambahan Krisan (Dendranthema sp.) Varietas Bakardi Putih dan Lolipop Ungu terhadap Pertumbuhan dan Hasil. Vegetalika. 2018. 7(4): 58-73

Sihombing. 2009. Budidaya Bunga Krisan Potong (Chrysanthemum sp.) Digilib.uns.ac.id. Diakses pada tanggal 31 Mei 2020

Sitompul dan Guritno. 1995. Pengaruh Penambahan Cahaya Pada 3 Varietas Krisan (Chrysanthemum morifolium) Tipe Spray. Jurnal Produksi Tanaman Vol. 5 No. 1, Januari 2017: 77 - 83 ISSN: 2527-8452

Sutater dan Sanjaya. 1992. Pengaruh Jenis Pupuk Terhadap Pertumbuhan dan

Produksi Tanaman Krisan. Balai Penelitian Tanaman Hias. J. Hort. 14(3):1-5, 2004

Sutanto. 2013. Pengaruh Lama Penyinaran Tambahan Krisan (Dendranthema sp.) Varietas Bakardi Puti Lolipop Ungu terhadap Pertumt an Hasil. Vegetalika. 2018. 7(4):

Triarsari. 2007. Krisan Potong. https://sinta.unud.ac.id. Diakses pada tanggal 08 Juni 2020

Warnita. 2015. Pengaruh Lama Penyinaran Tambahan Krisan (Dendranthema sp.) Varietas Bakardi Putih dan Lolipop Ungu terhadap Pertumbuhan dan Hasil. Vegetalika. 2018. 7(4): 58-73

Wilkins. 1990. Budidaya Krisan Bunga Potong Part 1. balithi.litbang.pertanian.go.id. diakses pada tanggal 27 Juli 2020

Wiryanta dan Bernardinus. 2002. Uji Empat Jenis Pupuk Kandang Terhadap Pertumbuhn dan Hasil Tanaman Cabai Keriting (Capsicum annum L.). Jurnal AGRIFOR Volume XII Nomor 1, Maret 2013. 